\title{
Kinetic Studies of Fenton Oxidation Reaction by UV-VIS Spectroscopy
}

\author{
Zhongde Dai, Gøril Flatberg, Heinz A. Preisig ${ }^{*}$, Liyuan Deng* \\ Department of Chemical Engineering, Norwegian University of Science and Technology (NTNU), Trondheim, Norway
}

\begin{abstract}
Chemical reaction engineering is one of the core courses for chemical engineering students. Laboratory exercise is an essential part of this course. The goal of this laboratory exercise is to demonstrate the possibility of using an in-situ spectroscopic method (UV-VIS spectroscopy) to investigate reaction kinetics. A solution of naphthol blue black (NBB) is oxidized by $\mathrm{H}_{2} \mathrm{O}_{2}$ through a Fenton oxidation process. In this exercise, the concentration of NBB was monitored by the UV-VIS spectroscopy, while the concentrations of $\mathrm{H}_{2} \mathrm{O}_{2}, \mathrm{FeSO}_{4}$ and different $\mathrm{pH}$ levels may be adjusted to enable students to obtain a wide range of reaction kinetic data. The reaction rate constant, $k_{a p p}$, can be estimated with a pseudo-first-order kinetic model. In addition, the reaction temperature was adjusted to investigate the decomposition activation energy $\left(E_{a}\right)$, which exhibited a value of $56.0 \pm 7 \mathrm{~kJ} \mathrm{~mol}^{-1}$.
\end{abstract}

Keywords Laboratory Instruction, Dyes /Pigments, Fenton and/or redox Reactions, UV-VIS spectroscopy

\section{Introduction}

Chemical reaction kinetics is the measurement of how quickly reactions occur, which is critical for discovering the mechanism of many reactions [1]. In undergraduate study, chemical reaction kinetics is a central concept in general chemistry as well as chemical reaction engineering. Generally, in chemical reaction kinetics study, typical pedagogical flow of teaching and reasoning in textbooks flows from postulated schemes to predicted results. On the other hand, the experience in the laboratory is opposite: students construct reaction schemes based on experiments data and extract a proper mathematical model to describe the reaction. Therefore, experimental exercise of measuring chemical kinetics is an essential pedagogical practice to enhance the understanding of the knowledge obtained from textbooks.

In the past years, different methods have been applied to demonstrate chemical kinetics in the lab, such as stopped-flow methods, chemical relaxation methods and spectrophotometry methods [2-4]. Among these methods, detecting chemical reaction kinetics in diluted aqueous solution using spectrophotometry is most commonly used

* Corresponding author:

heinz.a.preisig@ntnu.no (Heinz A. Preisig)

liyuan.deng@ntnu.no (Liyuan Deng)

Published online at http://journal.sapub.org/jlce

Copyright $(C 2018$ The Author(s). Published by Scientific \& Academic Publishing This work is licensed under the Creative Commons Attribution International

License (CC BY). http://creativecommons.org/licenses/by/4.0/ due to its simplicity and safety. This paper presents the design and practice of the laboratory exercise using UV-VIS spectroscopy to monitor the concentration changes of the reactants. The Fenton oxidation was chosen as example to study the chemical reaction kinetics. The reaction between iodide and peroxydisulfate as well as the decomposition of bezenediazonium ion are commonly used to study reaction kinetics. Compared to the other two processes, Fenton oxidation process is more economical for destructing hazardous pollutants in waste water [5-7]. Fenton oxidation process has been widely used as a powerful method for the degradation of various pollutants in wastewater. Due to the very active radicals produced in Fenton oxidation process, it is quite effective in removing almost any organic contaminant from waste water at near ambient temperature and pressure [8]. Therefore, employing Fenton oxidation as demonstration reaction is not only a good example to study reaction kinetics, but also gives the students an opportunity to learn some basic knowledge about a waste water treatment method. In addition, none of the reactants involved in this reaction are toxic or dangerous to handle, and the reaction condition is moderate. This lab exercise is thus considered easy and safe for the students. No special facilities and protective equipment are needed. Furthermore, UV-VIS spectroscopy is a safe, low cost and simple instrument, which is suitable for undergraduate students with limited laboratory experience [9]. 


\section{Background}

\subsection{Fenton Oxidation}

In waste water treatment, biodegradation is a predominant process. However, many pollutants are of a non-biodegradable nature. For instance, azo dyes has been widely used in textiles, cosmetics, printing and pharmaceutical industries, represent an important type of contaminants that are not biodegradable, can only be eliminated by the Fenton oxidation process. Fenton oxidation is one of the most advanced oxidation processes (AOPs) used in the waste water treatment, which normally involves a mixture of an iron catalyst and hydrogen peroxide in a aqueous solution [10]. In Fenton oxidation process, highly reactive hydroxyl radicals, which are very effective oxidative species (standard reduction potential of $\mathrm{HO}^{\circ}+\mathrm{H}^{+}+e^{-} \rightarrow \mathrm{H}_{2} \mathrm{O}$ is $2.8 \mathrm{~V}$ ), can be produced [11].

The hydroxyl radicals $\left(\mathrm{HO}^{\circ}\right)$ are produced due to the reaction of the reaction between hydrogen peroxide and ferrous ions (reaction 1 ). In a side reaction, ferric ions can further react with $\mathrm{H}_{2} \mathrm{O}_{2}$ to give $\mathrm{Fe}^{2+}$ and hydroperoxyl radicals (reaction 2 ), by which the redox cycle $\mathrm{Fe}^{2+}-\mathrm{Fe}^{3+}$ is accomplished. The concentration of the hydroxyl radicals in the reaction mixture can also be lowered by scavengers (reactions 3, 4 and 8). Reaction is usually carried out at low $\mathrm{pH}$ in order to avoid formation of ferric oxohydroxide precipitates. The main reactions taking place in Fenton process are listed in (1) - (8) [12]:

$$
\begin{aligned}
& \mathrm{Fe}^{2+}+\mathrm{H}_{2} \mathrm{O}_{2} \longrightarrow \mathrm{Fe}^{3+}+\mathrm{O}^{-}+\mathrm{HO}^{\bullet} \\
& \mathrm{Fe}^{3+}+\mathrm{H}_{2} \mathrm{O}_{2} \longrightarrow \mathrm{Fe}^{2+}+\mathrm{H}^{+}+\mathrm{HOO}^{\bullet} \\
& \mathrm{H}_{2} \mathrm{O}_{2}+\mathrm{HO}^{\bullet} \longrightarrow \mathrm{H}_{2} \mathrm{O}+\mathrm{HOO}^{\bullet} \\
& \mathrm{Fe}^{2+}+\mathrm{HO}^{\bullet} \longrightarrow \mathrm{Fe}^{3+}+\mathrm{OH}^{-} \\
& \mathrm{Fe}^{3+}+\mathrm{HOO}^{\bullet} \longrightarrow \mathrm{Fe}^{2+}+\mathrm{O}_{2} \mathrm{H}^{+} \\
& \mathrm{Fe}^{2+}+\mathrm{HOO}^{\bullet}+\mathrm{H}^{+} \longrightarrow \mathrm{Fe}^{3+}+\mathrm{H}_{2} \mathrm{O}_{2} \\
& 2 \mathrm{HOO}^{\bullet} \longrightarrow \mathrm{O}_{2}+\mathrm{H}_{2} \mathrm{O}_{2} \\
& \mathrm{H}^{+}+e^{-}+\mathrm{HO}^{\bullet} \longrightarrow \mathrm{H}_{2} \mathrm{O}
\end{aligned}
$$

\subsection{Kinetics of Degradation}

The oxidation of organic pollutants by the $\mathrm{HO}^{\circ}$ radicals can be described by several reaction mechanisms: $\mathrm{HO}^{\circ}$ radicals react with the organic pollutant by abstracting $H$ from $\mathrm{C}-\mathrm{H}, \mathrm{N}-\mathrm{H}$, or $\mathrm{O}-\mathrm{H}$ bonds, or by adding to $\mathrm{C}-\mathrm{C}$ bonds or conjugate aromatic rings. In any case, the large number of involved steps leads to a very complex kinetic model. A general rate law for the reactions with the key organic molecule can be written as follows [13]:

$$
r=-\frac{d c_{R H}}{d t}=k_{O H} c_{H O} c_{R H}+\sum_{i} k_{o x_{i}} c_{o x_{i}} c_{R H}
$$

The term $o x_{i}$ represents other oxidants that are present besides the $\mathrm{HO}^{\circ}$, such as ferryl $[\mathrm{Fe}(\mathrm{IV}) \mathrm{O}]^{2+}$ or $\mathrm{HOO}^{\circ}$. In order to simplify the model, only the hydroxyl radical is considered to be the active oxidant. The concentration of $\mathrm{HO}^{\circ}$ cannot be measured directly. It is considered to be large and constant under certain reaction conditions, leading to the pseudo-first reaction order where $\mathrm{HO}^{\circ}$ concentration is a part of the apparent rate constant $k_{\text {app }}(10,11)$.

$$
\begin{gathered}
r=-\frac{d c_{R H}}{d t}=k_{a p p} c_{R H} \\
\ln c_{R H}=\ln c_{R H_{0}}-k_{a p p} t
\end{gathered}
$$

Activation energy is normally defined as the minimum energy required to start a chemical reaction. It indicates the sensitivity of the reaction rate to temperature. For the Fenton oxidation reaction, the reaction rate is normally assumed to be exponentially dependent on the temperature (known as the Arrhenius equation, equation (12)). The two parameters, namely activation energy $\left(E_{a}\right)$ and pre-exponential factor $(A)$, are specific for each reaction and are assumed to remain constant over the validity range of the model.

$$
k_{\text {app }}=A e^{-\frac{E_{a}}{R T}}
$$

Where $A$ is the pre-exponential factor, $E_{a}$ is the activation energy, $T$ and $R$ is the temperature and gas constant, respectively.

\subsection{The Use of UV-VIS Spectroscopy for Kinetic Measurement}

Spectrophotometry is a commonly used method to experimentally determine the reaction rates $[14,15]$. The UV-VIS spectroscopy can measure the change of the concentrations of reactants or products over time. In this study, the UV-VIS spectroscopy was used to monitor the concentration of NBB (chemical structure shown in Figure 1) due to the absorption of the aromatic rings and azo group. Naphthol blue black (NBB) is an important acidic diazo dye in industrial applications, which has been widely used in the textile industry for dyeing wool, nylon, silk and textile printing [16]. On the other hand, NBB also presents a high toxicity to the environment because of the presence of phenolic, anilino, naphthalene and sulfonated groups (as shown in Figure 1). In addition, it has high photo- and thermal-stability [17]. Therefore, removing NBB from wastewater of textile industry is of great importance.

The main absorption peak at $618 \mathrm{~nm}$ is due to the azo group, whereas the peak at $320 \mathrm{~nm}$ is from the absorption of the aromatic rings. 


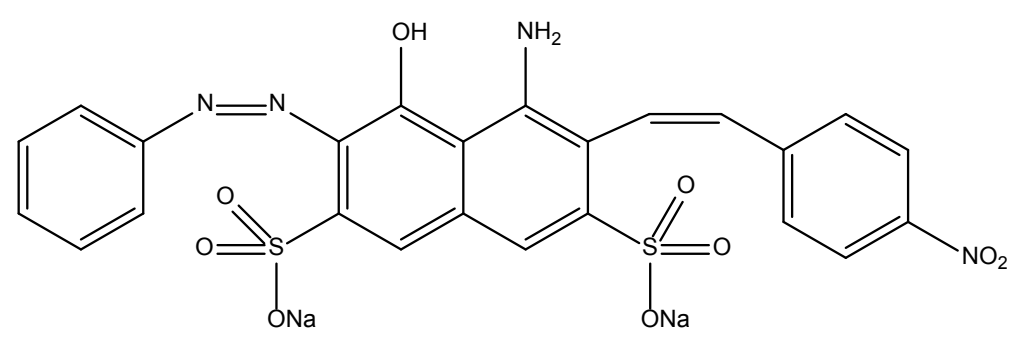

Figure 1. Chemical structure of Napthol blue black

The magnitude of the absorbance is proportional to its concentration and follows the Beer-Lambert equation. In case of NBB, the absorbance at $100 \%$ conversion $\left(A_{\infty}\right)$ approaches the absorbance of the reference sample $\left(A_{\text {ref }}\right)$, which is water for our case $\left(A_{\infty}=A_{\text {ref }}=0\right)$. Thus the rate constant can be estimated using linear regression by fitting $\ln \left(A_{R H O} / A_{R H}\right)$ versus the time $t$ (as shown in equation (13)).

$$
\ln \left(\frac{A_{R H_{0}}}{A_{R H}}\right)=k_{\text {app }} \cdot t
$$

Where the $A_{R H O}$ is the absorbance at time zero, while $A_{R H}$ is the absorbance at time $t$.

In case of activation energy, equation (13) can be rewritten as:

$$
\ln \left(k_{\text {app }}\right)=\ln (A)-\frac{E_{a}}{R T}
$$

Thus the activation energy $E_{a}$ can be found by fitting $\ln \left(k_{\text {app }}\right)$ versus $-1 / T$ via linear regression. A plot of $\ln (k)$ versus $-1 / T$ yields a straight line with a slope of $E_{a} / R$ and y-intercept $\ln (A)$, the natural logarithm of the Arrhenius constant.

\section{Experimental}

In the exercise, $\mathrm{NBB}$ and $\mathrm{FeSO}_{4} \cdot 7 \mathrm{H}_{2} \mathrm{O}$ was first mixed in a Erlenmeyer flask wrapped in aluminum foil, then $0.5 \mathrm{M}$ $\mathrm{H}_{2} \mathrm{SO}_{4}$ or $\mathrm{NaOH}$ solutions were added dropwisely until desired $\mathrm{pH}$ was reached $(\mathrm{pH}$ meter: METTLER TOLEDO, S220 SevenCompact ${ }^{\mathrm{TM}} \mathrm{pH} /$ Ion meter). A thermostated water bath was employed to maintain the temperature of the mixture over the experimental period. Once the desired temperature was stabilized, the $\mathrm{H}_{2} \mathrm{O}_{2}$ solution was added and simultaneously the UV-VIS spectroscopy (AvaLight-DH-S deuterium-halogen light source and an AvaSpec-2048 fiber optic spectrometer) was used to collect the NBB concentration information. The time started to add $\mathrm{H}_{2} \mathrm{O}_{2}$ in the solution was referred as $T_{0}$ and considered as the starting point of the reaction.

In the current exercise, 3 different versions of the experiments are available for the students: The first choice is to investigate the effects of the $\mathrm{pH}$ of the solution, while the second and third choices are to investigate the concentrations of $\mathrm{H}_{2} \mathrm{O}_{2}$ and $\mathrm{FeSO}_{4}$, respectively. Detailed molarities of all the stock solutions are listed in Table 1.
Table 1. Molarities of all stock solutions used in all the three

\begin{tabular}{|c|c|c|c|c|c|}
\hline & \multicolumn{5}{|c|}{ Version 1---changing $\mathrm{H}_{2} \mathrm{O}_{2}$} \\
\hline & $\mathrm{T}\left({ }^{\circ} \mathrm{C}\right)$ & {$\left[\mathrm{H}_{2} \mathrm{O}_{2}\right], \mathrm{M}$} & $\mathrm{pH}$ & [NBB], M & {$\left[\mathrm{FeSO}_{4}\right], \mathrm{M}$} \\
\hline Run 1 & 21 & $1.97 \times 10^{-4}$ & 3 & $1.62 \times 10^{-5}$ & $1.32 \times 10^{-4}$ \\
\hline Run 2 & 21 & $2.94 \times 10^{-4}$ & 3 & $1.62 \times 10^{-5}$ & $1.32 \times 10^{-4}$ \\
\hline Run 3 & 21 & $4.41 \times 10^{-4}$ & 3 & $1.62 \times 10^{-5}$ & $1.32 \times 10^{-4}$ \\
\hline Run 4 & 30 & $2.94 \times 10^{-4}$ & 3 & $1.62 \times 10^{-5}$ & $1.32 \times 10^{-4}$ \\
\hline \multirow[t]{3}{*}{ Run 5} & 40 & $2.94 \times 10^{-4}$ & 3 & $1.62 \times 10^{-5}$ & $1.32 \times 10^{-4}$ \\
\hline & \multicolumn{5}{|c|}{ Version 2--- changing pH } \\
\hline & $\mathrm{T}\left({ }^{\circ} \mathrm{C}\right)$ & {$\left[\mathrm{H}_{2} \mathrm{O}_{2}\right], \mathrm{M}$} & $\mathrm{pH}$ & [NBB], M & {$\left[\mathrm{FeSO}_{4}\right], \mathrm{M}$} \\
\hline Run 1 & 21 & $2.94 \times 10^{-4}$ & 2 & $1.62 \times 10^{-5}$ & $1.32 \times 10^{-4}$ \\
\hline Run 2 & 21 & $2.94 \times 10^{-4}$ & 3 & $1.62 \times 10^{-5}$ & $1.32 \times 10^{-4}$ \\
\hline Run 3 & 21 & $2.94 \times 10^{-4}$ & 4 & $1.62 \times 10^{-5}$ & $1.32 \times 10^{-4}$ \\
\hline Run 4 & 30 & $2.94 \times 10^{-4}$ & 3 & $1.62 \times 10^{-5}$ & $1.32 \times 10^{-4}$ \\
\hline \multirow[t]{3}{*}{ Run 5} & 40 & $2.94 \times 10^{-4}$ & 3 & $1.62 \times 10^{-5}$ & $1.32 \times 10^{-4}$ \\
\hline & \multicolumn{5}{|c|}{ Version 3 --- changing $\mathrm{FeSO}_{4}$} \\
\hline & $\mathrm{T}\left({ }^{\circ} \mathrm{C}\right)$ & {$\left[\mathrm{H}_{2} \mathrm{O}_{2}\right], \mathrm{M}$} & $\mathrm{pH}$ & [NBB], M & {$\left[\mathrm{FeSO}_{4}\right], \mathrm{M}$} \\
\hline Run 1 & 21 & $2.94 \times 10^{-4}$ & 3 & $1.62 \times 10^{-5}$ & $0.66 \times 10^{-4}$ \\
\hline Run 2 & 21 & $2.94 \times 10^{-4}$ & 3 & $1.62 \times 10^{-5}$ & $1.32 \times 10^{-4}$ \\
\hline Run 3 & 21 & $2.94 \times 10^{-4}$ & 3 & $1.62 \times 10^{-5}$ & $2.64 \times 10^{-4}$ \\
\hline Run 4 & 30 & $2.94 \times 10^{-4}$ & 3 & $1.62 \times 10^{-5}$ & $1.32 \times 10^{-4}$ \\
\hline Run 5 & 40 & $2.94 \times 10^{-4}$ & 3 & $1.62 \times 10^{-5}$ & $1.32 \times 10^{-4}$ \\
\hline
\end{tabular}
experiments

Normally two or three students are working together as a group. The total five runs of the experiment will take around 2.5 to 3 hours, depending on how well the students are prepared.

\section{Hazards}

Before the students can work in the lab they must go through the Safety Data Sheet (SDS) for all involved chemicals and work through the risk assessment form prepared for the experiment, including the apparatus card being completed by the experiment host. Due to the usage of $30 \% \mathrm{H}_{2} \mathrm{O}_{2}$ in the exercise, the possibility of causing serious eye damage must be highlighted to warn the students. The use of standard personal protective equipment (laboratory coat, nitrile gloves, and splash goggles) is also required. In this exercise, UV light is employed to detect the NBB concentration in the solution with an in situ probe. As an added precaution, students are instructed to switch off the UV light before removing the aluminum foil from the 
Erlenmeyer flask. Finally, as the solutions are acidic (pH 2-4) and containing iron $\left(\sim 0.02 \mathrm{mg} \mathrm{mL}^{-1}\right)$, the solutions should be neutralized and diluted prior to disposal.

\section{Results and Discussion}

\subsection{Effect of $\mathrm{H}_{2} \mathrm{O}_{2}$ Concentration, $\mathrm{pH}$ and $\mathrm{FeSO}_{4}$ Concentration on the $\mathbf{k}_{\text {app }}$}

Figure 2 clearly demonstrates the change of solution color before and after the Fenton oxidation. The experiment does not only demonstrate the efficiency of this Fenton oxidation, but it is also a good example of how the chemistry can be used in a real life application.

The effects of different conditions on the rate constant are shown in Figure 3. For $\mathrm{H}_{2} \mathrm{O}_{2}$ and $\mathrm{FeSO}_{4}$, it is quite obvious that higher concentration of $\mathrm{H}_{2} \mathrm{O}_{2}$ and $\mathrm{FeSO}_{4}$ could accelerate the reaction, resulting in increased reaction rate constant, corresponding to a larger slope of the line (as shown in Figure 3(A) and Figure 3(B)). As the concentration of $\mathrm{H}_{2} \mathrm{O}_{2}$ increases from $1.97 \times 10^{-4} \mathrm{M}$ to $4.41 \times 10^{-4} \mathrm{M}$, the rate constant increase from $0.0029 \mathrm{~s}^{-1}$ to $0.0061 \mathrm{~s}^{-1}$. In terms of the $\mathrm{FeSO}_{4}$, higher $\mathrm{FeSO}_{4}$ concentrations also lead to an increased rate constant (larger slope). It is worth mentioning that in many cases, the molar ratio of $\mathrm{H}_{2} \mathrm{O}_{2}$ to $\mathrm{FeSO}_{4}$ needs to be optimized to get the most effective oxidation efficiency [18].

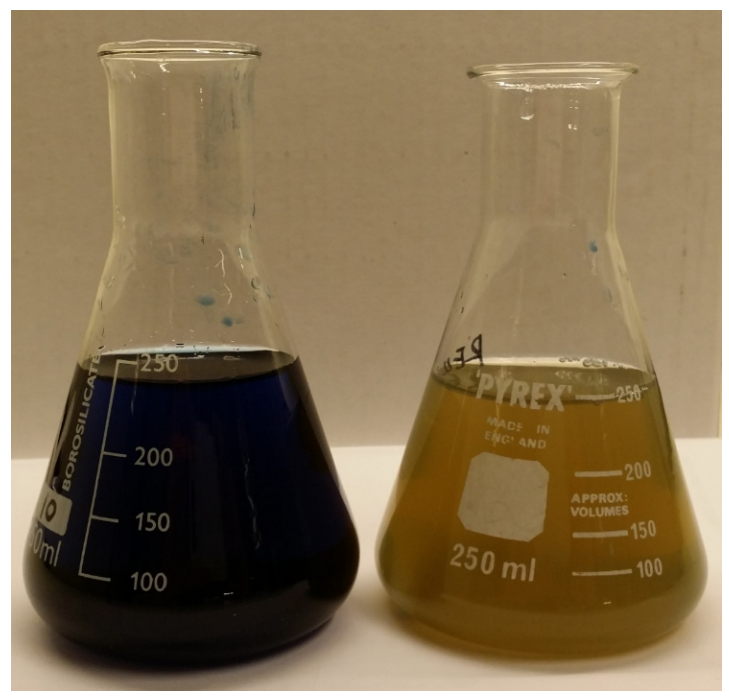

Figure 2. Optical images of the NBB solution before and after the Fenton oxidation reaction
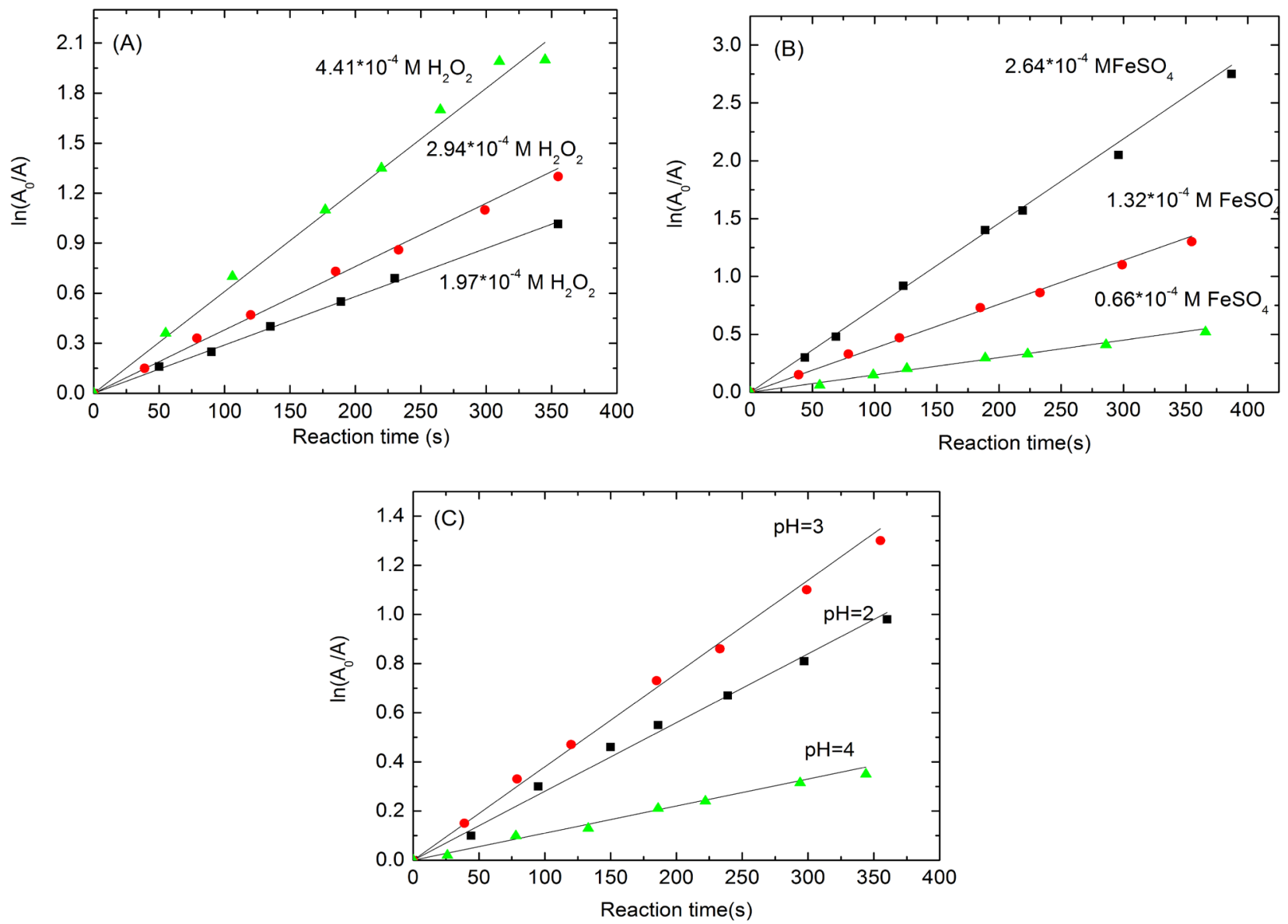

Figure 3. Illustrative example of the effect of different parameters on the rate constant, $(\mathrm{A}) \mathrm{H}_{2} \mathrm{O}_{2}$ concentration, $[\mathrm{NBB}]=1.62 \times 10^{-5}$, $\left[\mathrm{FeSO} \mathrm{F}_{4}\right]=1.32 \times 10^{-4}$ $\mathrm{M}, \mathrm{pH}=3$; (B) $\mathrm{FeSO}_{4}$ concentration, $[\mathrm{NBB}]=1.62 \times 10^{-5},\left[\mathrm{H}_{2} \mathrm{O}_{2}\right]=2.94 \times 10^{-4} \mathrm{M}, \mathrm{pH}=3$; and $(\mathrm{C}) \mathrm{pH},\left[\mathrm{H}_{2} \mathrm{O}_{2}\right]=2.94 \times 10^{-4} \mathrm{M},[\mathrm{NBB}]=1.62 \times 10^{-5},\left[\mathrm{FeSO} \mathrm{O}_{4}\right]=$ $1.32 \times 10^{-4} \mathrm{M}$. Experiment carried out at room temperature 
Table 2. The $k_{-a p p}\left(\times 10^{3}\right)$ values for all the nine experiments carried out at RT

\begin{tabular}{cccc}
\hline & Version 1, changing $\mathrm{H}_{2} \mathrm{O}_{2}$ & Version 2, changing pH & Version 3, changing FeSO \\
\hline Run 1 & $2.90 \pm 0.15\left(\left[\mathrm{H}_{2} \mathrm{O}_{2}\right]=1.97 \times 10^{-4} \mathrm{M}\right)$ & $2.80 \pm 0.15(\mathrm{pH}=2)$ & $1.50 \pm 0.17\left(\left[\mathrm{FeSO}_{4}\right]=0.66 \times 10^{-4}\right)$ \\
Run 2 & $3.80 \pm 0.30\left(\left[\mathrm{H}_{2} \mathrm{O}_{2}\right]=2.94 \times 10^{-4} \mathrm{M}\right)$ & $3.80 \pm 0.34(\mathrm{pH}=3)$ & $3.80 \pm 0.29\left(\left[\mathrm{FeSO}_{4}\right]=1.32 \times 10^{-4}\right)$ \\
Run 3 & $6.10 \pm 0.61\left(\left[\mathrm{H}_{2} \mathrm{O}_{2}\right]=4.41 \times 10^{-4} \mathrm{M}\right)$ & $1.10 \pm 0.20(\mathrm{pH}=4)$ & $7.30 \pm 1.10\left(\left[\mathrm{FeSO}_{4}\right]=2.64 \times 10^{-4}\right)$ \\
\hline
\end{tabular}

The oxidation of NBB as a function of $\mathrm{pH}$ is shown in Figure 3(C). In contrast to the effects of $\mathrm{H}_{2} \mathrm{O}_{2}$ and $\mathrm{FeSO}_{4}$ on the reaction, the change of $\mathrm{pH}$ generates a more complex pattern in the results. The reaction rate constant rises at a very low $\mathrm{pH}$, and goes through a maximum before it decreases again. This behavior is clearly observable in the experiment as the discoloration efficiency of NBB is seen to be strongly $\mathrm{pH}$ dependent. It is commonly accepted that the most effective $\mathrm{pH}$ value is approximately 3 [19]. The decrease in oxidation rate at $\mathrm{pH}>3$ is likely due to the formation of $\mathrm{Fe}(\mathrm{OH})_{3}$, which has lower catalytic activity in the decomposition of $\mathrm{H}_{2} \mathrm{O}_{2}$ [18]. When $\mathrm{pH}$ value is lower than 3, a more complex species $\left[\mathrm{Fe}\left(\mathrm{H}_{2} \mathrm{O}\right)_{6}\right]^{2+}$ may be formed, which has a much lower reaction rate constant with $\mathrm{H}_{2} \mathrm{O}_{2}$, and therefore produces fewer $\mathrm{HO}^{\circ}$ radicals [20]. Additionally, at a very low $\mathrm{pH}$, the reaction of $\mathrm{Fe}^{3+}$ with $\mathrm{H}_{2} \mathrm{O}_{2}$ is inhibited [21]. All these side reactions result in a lower overall decoloring rate and lower $k_{a p p}$. In the present study, it is found that $\mathrm{pH}$ at 2 has a slightly lower rate constant, which is in a good agreement to many other reports [21,22].

\subsection{Comparison of Rate Constant at Different Wavelength}

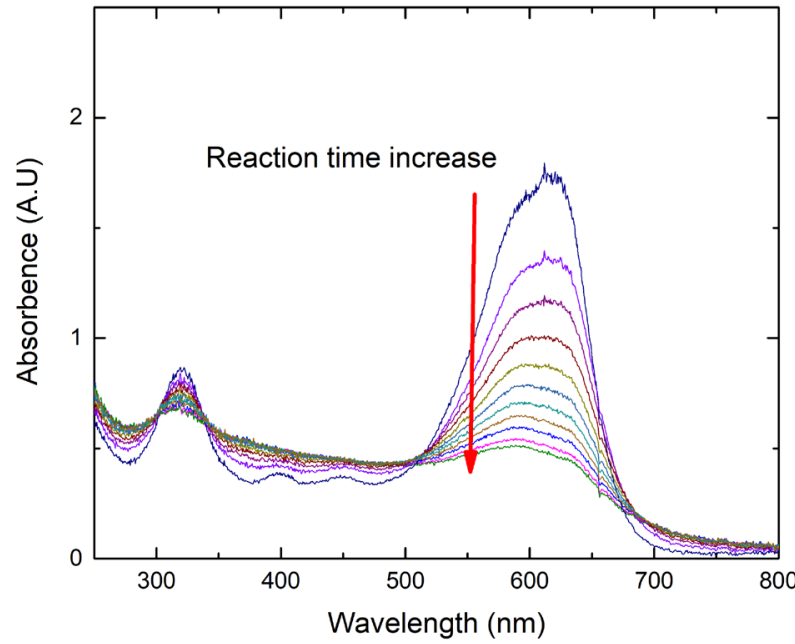

Figure 4. Absorbance of NBB over reaction time. Reaction condition: $\left[\mathrm{H}_{2} \mathrm{O}_{2}\right]=2.94 \times 10^{-4} \mathrm{M},[\mathrm{NBB}]=1.62 \times 10^{-5},\left[\mathrm{FeSO}_{4}\right]=1.32 \times 10^{-4} \mathrm{M}, \mathrm{pH}=3$ at room temperature

Figure 4 presents the absorbance of the azo group (618 $\mathrm{nm})$ and the aromatic rings $(320 \mathrm{~nm})$ over time. It is obvious that the peak at $618 \mathrm{~nm}$ reduces drastically over time, while there is little variation in the peak at $320 \mathrm{~nm}$, which clearly shows that the Fenton oxidation is more effective for oxidation of the azo group $(618 \mathrm{~nm})$ than the aromatic rings $(320 \mathrm{~nm})$ for NBB.

\subsection{Activation Energy Calculation}

Figure 5 shows the natural logarithm of $k_{a p p}$ plotted against $-1 / T$, which gives the activation energy (based on equation (14)). The slope of the linear regression is multiplied by the universal gas constant, $R\left(R=8.314 \mathrm{~J} \mathrm{~K}^{-1}\right.$ $\mathrm{mol}^{-1}$ ), yielding the activation energy $\left(E_{a}\right)$. In our study, an $E_{a}$ value of $56.0 \pm 7 \mathrm{~kJ} \mathrm{~mol}^{-1}$ was obtained. It is worth mentioning that different compounds have different activation energy in Fenton oxidation process [23, 24]. Therefore, due to the big variety of the activation value, it is difficult to use literature data to validate/confirm their results.

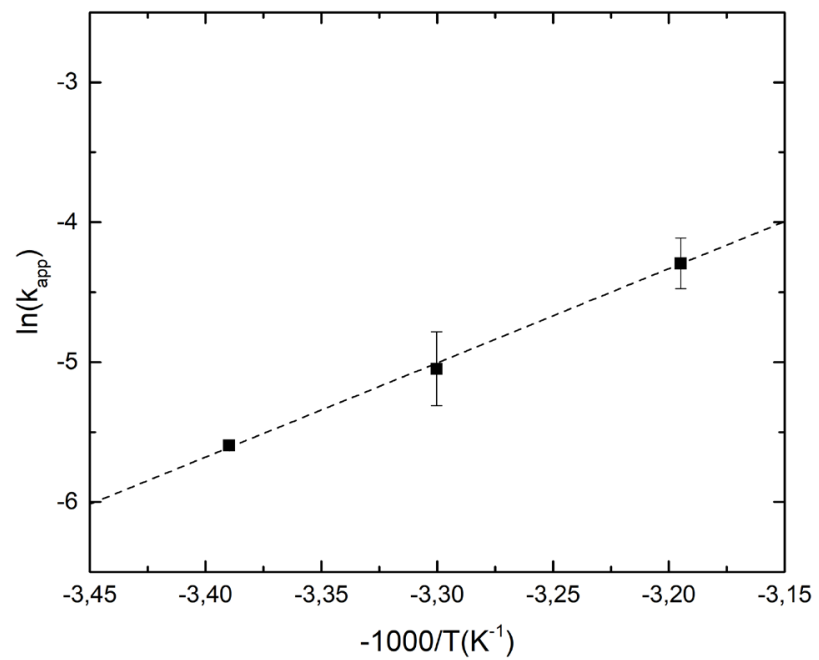

Figure 5. Illustrative example of the activation energy calculation. Reaction condition: $\left[\mathrm{H}_{2} \mathrm{O}_{2}\right]=2.94 \times 10^{-4} \quad \mathrm{M}, \quad[\mathrm{NBB}]=1.62 \times 10^{-5}$, $\left[\mathrm{FeSO}_{4}\right]=1.32 \times 10^{-4} \mathrm{M}, \mathrm{pH}=3$. Experiment carried out at room temperature, 30 and $40^{\circ} \mathrm{C}$

Several factors are the source of uncertainty in this experiment. First of all, although the flask was covered with aluminum foil, it needs to be opened during the addition of $\mathrm{H}_{2} \mathrm{O}_{2}$ into the reaction mixture, thus the UV-VIS detector may get UV signal from the atmosphere. In addition, the $\mathrm{pH}$ measurement, temperature measurement and the volume measurement are not noise free. In particular, the inaccurate control of the reaction temperature $\left( \pm 2{ }^{\circ} \mathrm{C}\right)$ may resulted in bigger error when calculating the activation energy. Furthermore, the experiment takes approximately 2.5-3 hours, which implies that the students have typically only one run for each test point. Last but not least, the lack of laboratory experience makes the mistakes in taking the sampling the largest source of errors. 


\section{Conclusions}

The design and implementation of the laboratory exercise using UV-VIS spectroscopy to investigate the chemical reaction kinetics of decomposition of NBB by Fenton oxidation has been successful. This exercise employs relatively small, inexpensive, simple and readily available pieces of equipment and can give the effective and hands-on experimental training to undergraduate students enrolled in different chemistry / chemical engineering courses. According to the results, the chemical kinetics of NBB decomposition by Fenton oxidation reaction can be easily studied in a laboratory period of 2.5 to 3 hours. The rate constant $\left(k_{a p p}\right)$ and activation energy $\left(E_{a}\right)$ can be investigated under different conditions. Furthermore, by analyzing the data obtained from this lab exercise, additional learning objectives can be introduced to students (e.g. determination of order w.r.t. to each reactant or catalyst).

\section{Associated Content}

The supporting information is available, including: 1. List of chemical and reagents; 2. Experiment procedure; 3. Data treatment; 4. Exercise implementation and evaluation; 5. Work Plan Guidelines, 6. Report Guidelines; 7. Grading criteria and 8. Experimental introduction.

\section{ACKNOWLEDGMENTS}

Dr. Mikael Hammer is gratefully acknowledged for reviewing this paper.

\section{REFERENCES}

[1] Mickey, C.D., Chemical Kinetics: Reaction Rates. Journal of Chemical Education, 1980. 57(9): p. 659.

[2] Mark E. Davis, R.J.D., Fundamentals of Chemical Reaction Engineering. 2003.

[3] Benz, L., et al., Employing Magnetic Levitation To Monitor Reaction Kinetics and Measure Activation Energy. Journal of Chemical Education, 2012. 89(6): p. 776-779.

[4] Carraher, J.M., S.M. Curry, and J.-P. Tessonnier, Kinetics, Reaction Orders, Rate Laws, and Their Relation to Mechanisms: A Hands-On Introduction for High School Students Using Portable Spectrophotometry. Journal of Chemical Education, 2016. 93(1): p. 172-174.

[5] Duesterberg, C.K., S.E. Mylon, and T.D. Waite, pH Effects on Iron-Catalyzed Oxidation using Fenton's Reagent. Environmental Science \& Technology, 2008. 42(22): p. 8522-8527.

[6] Masomboon, N., C. Ratanatamskul, and M.C. Lu, Chemical Oxidation of 2,6-Dimethylaniline in the Fenton Process. Environmental Science \& Technology, 2009. 43(22): p.
8629-8634.

[7] Rivas, F.J., et al., Fenton's oxidation of food processing wastewater components. Kinetic modeling of protocatechuic acid degradation. Journal of Agricultural and Food Chemistry, 2005. 53(26): p. 10097-10104.

[8] Rahim Pouran, S., A.R. Abdul Aziz, and W.M.A. Wan Daud, Review on the main advances in photo-Fenton oxidation system for recalcitrant wastewaters. Journal of Industrial and Engineering Chemistry, 2015. 21: p. 53-69.

[9] Czegan, D.A.C. and D.K. Hoover, UV-Visible Spectrometers: Versatile Instruments across the Chemistry Curriculum. Journal of Chemical Education, 2012. 89(3): p. 304-309.

[10] Neyens, E. and J. Baeyens, A review of classic Fenton's peroxidation as an advanced oxidation technique. Journal of Hazardous Materials, 2003. 98(1-3): p. 33-50.

[11] Nalliah, R.E., Oxone/Fe $\mathrm{Fe}^{2+}$ Degradation of Food Dyes: Demonstration of Catalyst-Like Behavior and Kinetic Separation of Color. Journal of Chemical Education, 2015. 92(10): p. 1681-1683.

[12] Bokare, A.D. and W. Choi, Review of iron-free Fenton-like systems for activating $\mathrm{H} 2 \mathrm{O} 2$ in advanced oxidation processes. Journal of Hazardous Materials, 2014. 275: p. 121-135.

[13] Sun, J.-H., et al., A kinetic study on the degradation of p-nitroaniline by Fenton oxidation process. Journal of Hazardous Materials, 2007. 148(1): p. 172-177.

[14] Galloway, K.R., S.L. Bretz, and M. Novak, Paper Chromatography and UV-Vis Spectroscopy To Characterize Anthocyanins and Investigate Antioxidant Properties in the Organic Teaching Laboratory. Journal of Chemical Education, 2015. 92(1): p. 183-188.

[15] Via, G., et al., Decay Kinetics of UV-Sensitive Materials: An Introductory Chemistry Experiment. Journal of Chemical Education, 2015. 92(4): p. 747-751.

[16] Şaşmaz, S., et al., Decolorization Potential of Some Reactive Dyes with Crude Laccase and Laccase-Mediated System. Applied Biochemistry and Biotechnology, 2011. 163(3): p. 346-361.

[17] Bechiri, O. and M. Abbessi, Catalytic oxidation of naphtol blue black in water: Effect of Operating Parameters and the Type of Catalyst. Journal of Water and Environmental Nanotechnology, 2017. 2(1): p. 9-16.

[18] Fan, H.J., et al., Degradation pathways of crystal violet by Fenton and Fenton-like systems: Condition optimization and intermediate separation and identification. Journal of Hazardous Materials, 2009. 171(1-3): p. 1032-1044.

[19] Bechiri, O., M. Abbessi, and M.E. Samar, Decolorization of organic dye (NBB) using $\mathrm{Fe}(I I I) P 2 W 12 \mathrm{Mo5} / \mathrm{H} 2 \mathrm{O} 2$ system. Desalination and Water Treatment, 2013. 51(31-33): p. 6110-6114.

[20] Gallard, H., J. De Laat, and B. Legube, Spectrophotometric study of the formation of iron(III)-hydroperoxy complexes in homogeneous aqueous solutions. Water Research, 1999. 33(13): p. 2929-2936.

[21] Tang, W.Z. and C.P. Huang, 2,4-dichlorophenol oxidation kinetics by Fenton's reagent. Environmental Technology, 1996. 17(12): p. 1371-1378. 
[22] Kang, Y.W. and K.Y. Hwang, Effects of reaction conditions on the oxidation efficiency in the Fenton process. Water Research, 2000. 34(10): p. 2786-2790.

[23] Karthikeyan, S., et al., A new approach for the degradation of high concentration of aromatic amine by heterocatalytic
Fenton oxidation: Kinetic and spectroscopic studies. Journal of Molecular Liquids, 2012. 173: p. 153-163.

[24] Xu, H., et al., Fenton Reagent Oxidation and Decolorizing Reaction Kinetics of Reactive Red SBE. Energy Procedia, 2012. 16: p. 58-64. 